Não me olhe como vê: o não lugar das memórias, ...

\title{
Não me olhe como vê: o não lugar das memórias, narrativas e trajetórias das mulheres negras nos museus de Salvador
}

\author{
Joana Angélica Flores Silva ${ }^{1}$
}

\section{Resumo:}

O presente texto é resultado da dissertação apresentada no Programa de Pós-Graduação em Museologia da Universidade Federal da Bahia, intitulada: A representação das mulheres negras nos museus de Salvador: uma análise em branco e preto, que trata de um estudo de caráter crítico, acerca do lugar que é atribuído às mulheres negras, nas exposições de longa duração, nos museus de tipologia histórica em Salvador, Bahia, Brasil. O artigo propõe uma reflexão durante o processo de significação dos objetos das coleções que tratam somente das mulheres negras no contexto da escravidão. Nesse processo, é discutido o papel dos profissionais de museus e a forma como os mesmos hierarquizam coleções e subalternizam sujeitos. Há uma apropriação do meu lugar de fala como pesquisadora e militante da causa da mulher negra, no contexto de construção de lugares de memórias que tratem das trajetórias e narrativas dessas mulheres. $O$ artigo traz o aporte teórico de Freire (1989), para tratar das relações entre o homem e o mundo; Hooks (2013) sustenta a discussão do lugar da intelectual negra na academia; Menezes (1994) e Cury (2005), para tratar das exposições museológicas, dentre outras contribuições.

Palavras-chave: mulheres negras, museus de Salvador, representação, Museologia.

\section{Abstract:}

\footnotetext{
${ }^{1}$ Joana Angélica Flores Silva. Museóloga da Universidade Federal do Recôncavo da Bahia. Graduada e mestra em Museologia pela Universidade Federal da Bahia.
} 
The present text is a result of the dissertation presented in the Postgraduate Program in Museology of the Federal University of Bahia, entitled: The representation of black women in the museums of Salvador: a black and white analysis that deals with a study of a critical, About the place that is attributed to black women, in the long-term exhibitions, in the museums of historical typology in Salvador, Bahia, Brazil. The article proposes a reflection during the process of meaning of the objects of the collections that treat only the black women in the context of the slavery. In this process, the role of museum professionals and how they rank collections and subalternate subjects is discussed. There is an appropriation of my speaking place as a researcher and militant of the cause of the black woman, in the context of the construction of places of memories that deal with the trajectories and narratives of these women. The article brings the theoretical contribution of Freire (1989), to deal with the relations between man and the world; Hooks (2013) sustains the discussion of the place of the black intellectual in the academy; Menezes (1994) and Cury (2005), to deal with museological expositions, among other contributions.

Keywords: black women, museums of Salvador, representation, Museology.

\section{Introdução}

O texto aqui apresentado decorre de uma investigação que venho realizando, sobre a representação das mulheres negras nos museus de Salvador. A pesquisa traz como desdobramentos temas como, ausências das mulheres negras nas exposições de longa duração; o processo de significação dos objetos a partir da interpretação dos interlocutores (profissionais de museus); os lugares que são dispostos os objetos que fazem analogia às mulheres negras; as narrativas produzidas pelos museus em relação a participação das mulheres negras no processo de construção social do país; a posição de subalterna que os discursos expográficos alocam as mulheres negras dentre outras.

Tratar dessas questões no campo da museologia requer assegurar um lugar de voz como mulher negra nesse cenário de 
Não me olhe como vê: o não lugar das memórias, ...

discussões acadêmicas, em um momento propício aos temas voltados às desigualdades de gênero, frutos de conquistas sociais e políticas, principalmente com a criação do Estatuto da Igualdade Racial quando afirma em seus postulados, no Art. 10, inciso III "desigualdade de gênero e raça: assimetria existente no âmbito da sociedade que acentua a distância social entre mulheres negras e os demais segmentos sociais" (BRASIL, 2010).

Essa determinação trazida pelo Estatuto reitera a relevância da inserção das mulheres negras nos debates museológicos e também nos museus, por serem também de sua responsabilidade, o compromisso profissional com esse grupo.

A não estereotipização da imagem da mulher negra nos espaços responsáveis pela institucionalização da memória fortalece o imaginário coletivo em relação ao papel secundário que é atribuído a esse grupo em detrimento ao lugar de superioridade atribuído às mulheres não negras, em Salvador, abordagem pertinente, por ser assegurada pelo Conselho Internacional de Museus (ICOM) como responsabilidade dos museus o seu compromisso em assumir questões de cunho social, o que é evidenciado em sua definição ao afirmar que o mesmo é,

Uma instituição permanente, sem fins lucrativos, a serviço da sociedade e do seu desenvolvimento, aberta ao público e que adquire, conserva, investiga, difunde e expõe os testemunhos materiais do homem e de seu entorno, para educação e deleite da sociedade. O museu é uma instituição permanente sem fins lucrativos, ao serviço da sociedade e do seu desenvolvimento, aberta ao público, que adquire, conserva, investiga, comunica e expõe o património material e imaterial da humanidade e do seu meio envolvente com fins de educação, estudo e deleite. (2001, p. 1)

Essa acepção me leva a indagar a partir das ações desenvolvidas pelas Instituições Museológicas, principalmente em relação a temas sobre o século XIX, quem de fato se deleita com os "testemunhos materiais" apresentados pelos museus e como 
compreende o desenvolvimento de uma sociedade, a partir da caracterização dos objetos ali expostos, ocupando o lugar de discursos construídos sobre uma narrativa, onde impera a verdade que legitima o lugar e o não lugar de determinados sujeitos na sociedade ali representada?

E ainda obedecendo à lógica desse entendimento, quais lembranças nos trazem esses testemunhos e qual sociedade, se desenvolveu com esse deleite? Qual sociedade está ali representada para o deleite dos que conseguem por alguns instantes, reproduzir um "ai" de gozo, diante das permanências da personificação do quase ausente objeto, que em meio a um cenário construído, tornam-se representações muitas vezes de lembranças de tempos cruéis da historiografia oficial que aconteceu em várias partes do mundo?

Diante da perspectiva trazida pelo conceito de memória, apresentado nos pontos de referências que as estruturam, podemos refletir sobre o lugar dos objetos nos museus, sua carga semântica em torno do repertório imbricado nos mesmos quando estão ali a representar a mulher negra numa posição coadjuvante, nas exposições museológicas.

E o que são as exposições museológicas? De acordo com Cury (2005), "a exposição é o local de encontro e relacionamento entre o que o museu quer apresentar e como deve apresentar visando um comportamento ativo do público e à sua síntese subjetiva". (p. 42).

Daí, os corpos das mulheres negras cumprirem somente o papel de suporte expositivo dos símbolos de representação de poder de um tempo - os objetos - visando a busca por "esse comportamento ativo", podendo esse mesmo público fazer uma leitura da subjetividade da composição através do jogo dos recursos técnicos expográficos que culminam na construção dos discursos museológicos: a luz, a localização dos textos e das 
Não me olhe como vê: o não lugar das memórias, ...

legendas, a cor das paredes internas das vitrines, a disposição dos painéis ${ }^{2}$ etc.

Há também um jogo de símbolos e de simbologias, à qual apropriando-me do "poder simbólico" de Bourdieu (1989), ao afirmar que "o poder simbólico é, com efeito, esse poder invisível o qual só pode ser exercido com a cumplicidade daqueles que não querem saber que lhe estão sujeitos ou mesmo que o exercem" ( $p$. 7-8).

Nesse sentido, o corpo das mesmas ocupa o lugar da alegoria ao ser disposto cenograficamente, e assim atender às ideologias, filosofias e jogos políticos constituídos pelos museus, inserindo-o no ritual do preservado e na exposição de longa duração torna-se o espetáculo. É importante assim que se desloquem os objetos, realoquem os discursos e (re)interpretemnos na atualidade, no lugar de testemunhos materiais da história.

Nesse universo de "deleite" que a exposição museológica pode apresentar, é necessário que os(as) profissionais da área, reflitam sobre esse não lugar do objeto na exposição. Que proporcionem diálogos entre o artístico, o histórico (sacralizado), a representação construída sobre os corpos dessas mulheres quando figuram como suportes expositivos, ou mesmo alegorias do real. Que se discutam sobre a ausência de narrativas que possibilitem a desconstrução de um imaginário coletivo que tendência a legitimação e personificação da imagem da mulher negra na condição de sujeito sempre subalterno.

Nesse contexto, posso afirmar que as memórias trazidas por essas instituições, são memórias oriundas de um repertório

\footnotetext{
${ }^{2}$ Essas especificidades sobre o discurso museológico referem-se aos museus de tipologia histórica em Salvador, Bahia, Brasil, pesquisados na dissertação intitulada "A representação das mulheres negras nos museus de Salvador:uma análise em banco e preto", que são: Museu de Arte da Bahia (MAB), Museu Nacional de Enfermagem Anna Nery (MuNEAN), Museu Henriqueta Catharino, Museu de Ex-Votos, Museu Eugênio Teixeira Leal, Museu da Misericórdia, Museu Ilê Ohun Lailai.
} 
construído e certificado a partir da espetacularização dos objetos quando os corpos negros eram apresentados nas exposições universais no século XIX, para reforçar o ainda existente lugar de alicerce das recordações "nacionalistas".

\section{Somente torços e balangandãs: as rasuras dos discursos narrativos nas exposições museológicas em Salvador-Bahia}

Ao imaginar que as trajetórias das mulheres negras não conseguem ser descritas somente numa penca de balangandãs, ${ }^{3}$ ou mesmo, num conjunto de joias intituladas como de "joias de crioulas"; ${ }^{4}$ em meia dúzia de saias, ${ }^{5}$ ou mesmo numa medalha exposta num cenário considerado "nobre" por estar ao lado de D. Pedro II, ${ }^{6}$ fico novamente a me indagar? Onde estarão as narrativas das mulheres negras, se nesses espaços de memória, essa ausência é uma constante? Quem assegura o direito da perpetuação das memórias dessas mulheres e às futuras gerações de meninas e jovens negras? E as gerações de negras anteriores às mesmas? Suas histórias, suas conquistas, suas contribuições sociais para o cenário político, econômico e cultural do país, quem preserva?

3 Segundo Farelli (1981), é "um conjunto de peças de prata, ou outro qualquer metal, presas em uma galera ou nave, comumente chamada de argola ou aro. "laôs e laorixás" trazem-na pendentes à cintura, numa corrente fechada por uma borboleta, assim denominada por ser um parafuso encimado por duas pequeninas asas semelhantes às daquele lepidóptero".

4 A referência se faz à legenda da vitrine do Museu de Arte da Bahia, em Salvador, Bahia, Brasil, citada na página 37 da dissertação "A representação das mulheres negras nos museus de Salvador: uma análise em branco e preto" (2015), bem como, segundo Godoy (2006), em sua publicação intitulada, Círculo das Contas: joias de crioulas baianas, a mesma afirma ser "uma das mais destacadas coleções do Museu Carlos Costa Pinto é a de joias de crioulas baianas" (p. 13).

5 Referência às saias dispostas na vitrine da exposição de longa duração do Museu do Traje e do Têxtil, em Salvador, Bahia, Brasil.

6 No Museu Eugênio Teixeira Leal, em Salvador, Bahia, Brasil, a medalha de Mãe Menininha do Gantois encontra-se disposta na vitrine intitulada "o artista gravador" na sala de "Medalhas e Condecorações Nacionais e Estrangeiras. Ver Silva (2015). 
Não me olhe como vê: o não lugar das memórias, ...

É inaceitável que as memórias das mulheres negras estejam somente ligadas ao tabuleiro da baiana, com todo o respeito que a elas tenho -, nem somente às suas lindas roupas volumosas, ${ }^{7}$ pois as narrativas e trajetórias das mesmas vão além do que vemos e do que vendem.

Dessa forma, acredito que os museus podem avançar e passar a ser o lugar que vá além do "deleite" para o seu público, mas, que também conforme afirma Menezes (1994),

Não sejam espaços anacrônicos e nostálgicos, receosos de se contaminarem com os vírus da sociedade de massas, mas antes, poderão constituir extraordinárias vias de conhecimento e exame dessa mesma sociedade. Serão, assim, bolsões para os ritmos personalizados de fruição e para a formação da consciência crítica, que não pode ser massificada. (p. 14, grifo nosso)

Se assim os forem, poderão os museus e seus públicos se responsabilizarem pela indagação das informações que vão além da forma, da cor e da origem dos objetos ali expostos. Indagar e questionar as ausências desses espaços e o que neles contém. Ouvir as narrativas que não aparecem, mas, que deixam brechas para novas e possíveis narrativas. É possível nesse sentido, brincar com o invisível e, se porventura, conseguirem-se ainda deleitar-se com exposições de longa duração, dessa natureza, percebam que o que se olha não pode ser o que se quer ver, pois o que parece apresentado é na verdade o que está silenciado.

\section{Memórias e narrativas das mulheres negras nos museus: silêncio ou esquecimento?}

7 No Museu Eugênio Teixeira Leal. Na sala da “História do Dinheiro" encontra-se a reprodução da cédula de cinquenta mil cruzeiros reais onde figura a imagem tradicional da Baiana, cuja representatividade é sempre atrelada a mulher negra. Ver a dissertação: A representação das mulheres negras nos museus de Salvador: um diálogo em branco e preto. 
Falar de silêncio a partir das ausências no Campo da Museologia é afirmar que ainda na atualidade, os museus não dão conta de desenvolver ações que possibilitem estreitar as relações entre o sujeito e o meio (mundo) tendo como interlocutor o objeto e a sua significação. No sentido da pluralidade como afirma Freire (1989),

As relações que o homem trava no mundo com o mundo (pessoais, impessoais, corpóreas e incorpóreas) apresentam uma ordem tal de características que as distinguem totalmente dos puros contatos, típicos da outra esfera animal. Entendemos que, para o homem, o mundo é uma realidade objetiva, independente dele, possível de ser conhecida. (p. 39)

O pensamento do autor corrobora para que possamos refletir sobre o lugar dos sujeitos no mundo e nas representações trazidas pela historiografia e reproduzida pelos museus, ao cerceálos de forma a torná-los indivíduos fora do mundo, descontextualizados, isolados.

No discurso de Freire (1989), a ideia de "pluralidade nas relações do homem com o mundo" (p. 39) corrobora para a pesquisa, no sentido de tornar os museus veículos de escuta e se possível dar voz aos sujeitos tornando-os capazes de criticarem-se, desafiarem-se, apropriarem-se e com isso tornarem-se visíveis.

Os museus, diante da ação de comunicar-se, fecham-se em seus mundos e com isso se isolam dos vários grupos sociais, o que é perceptível no discurso que produzem através de suas exposições. Essas, quase sempre enciclopédicas, carregadas de informações em textos e/ou legendas cujos conteúdos reforçam o lugar de homens e mulheres brancos, partícipes de da elite política e intelectual do país.

Em Salvador, Bahia, Brasil, os museus, ao representarem através dos objetos as mulheres não negras em suas exposições, reforçam a permanência e a supremacia das mesmas enaltecendo nome, sobrenome e filiação o que destaca as referências apontadas 
Não me olhe como vê: o não lugar das memórias, ...

pela pesquisa em relação à construção das memórias das mulheres negras, excluídas da historiografia oficial enquanto concedentes do processo de desenvolvimento do país.

Para discutir as ausências dessas memórias nas Instituições Museológicas, utilizo-me da definição trazida pelo Estatuto dos Museus, quando afirma,

Art. $1^{\circ}$ : Consideram-se museus, para os efeitos desta Lei, as instituições sem fins lucrativos que conservam, investigam, comunicam, interpretam e expõem, para fins de preservação, estudo, pesquisa, educação, contemplação e turismo, conjuntos e coleções de valor histórico, artístico, científico, técnico ou de qualquer outra natureza cultural, abertas ao público, a serviço da sociedade e de seu desenvolvimento. (BRASIL, 2009)

Sendo assim, é importante analisar do ponto de vista das ausências, quais as brechas encontradas nessa definição que corroboram para o não lugar de determinados sujeitos, enquanto atores e atrizes sociais na dinâmica da construção e da representação desses conjuntos mencionados pelo Estatuto e indagarmos: A quem de fato se deve atribuir à ausência das mulheres negras nas discussões de preservação das suas memórias?

Pollak (1992), na sua obra Memória e identidade social, utiliza-se do termo a "solidificação da memória" como contribuição para a compreensão do tema, no processo de construção da memória coletiva e individual quando as narrativas de "história de vida" por quem vivencia seus fatos ou períodos da vida sente dificuldade em isolar informações e voltam sempre aos mesmos acontecimentos. Nesse sentido, a responsabilidade dos entrevistadores (as)/(receptores(as) trazidos pelo autor, mas, no contexto dos museus, são os profissionais da área que irão interpretar os fatos. Pollak (1992) afirma que,

Em certo sentido, determinados números de elementos tornamse realidade, passam a fazer parte a própria essência da pessoa, 
muito embora tantos outros acontecimentos e fatos possam se modificar em função dos interlocutores, ou em função do movimento da fala. (p. 201).

O pensamento do autor corrobora para a interpretação de que, nesse contexto, a repetição dos fatos descritos encontra o seu lugar de permanência simbólica depositadas nas mãos de quem controla os discursos hegemônicos desse país, bem como encontram-se nos museus também, enquanto espaços de poder e que reproduzem suas narrativas sem buscar atender aos princípios estabelecidos nas Políticas de Igualdade Racial no Brasil, elaboradas nos últimos anos, lacuna nas discussões museológicas que distanciam essas Instituições dos problemas sociais do país.

Não se dialoga nos museus sobre a fome, a má distribuição de renda, a atuação da polícia nos bairros periféricos; o genocídio negro (apenas o Museu Afro-Brasileiro da Universidade Federal da Bahia fez uma exposição ${ }^{8}$ sobre o tema, em Salvador, Bahia Brasil); a violência contra a mulher; o número alarmante de casos de violência contra a mulher negra; os crimes de homofobia; o frio dos moradores de rua; a participação racista dos meios de comunicação local que em determinadas emissoras, não têm em sua grade de programação jornalística, negros e negras como âncoras; a ausência de diálogos entre os museus e as escolas para discutir a aplicabilidade da Lei n. 10.639/13 em seus espaços, dentre outras questões.

Logo, essa sequência de ausências responde em que sentido os museus optaram por uma repetição de fatos que corroboram para enaltecer determinados grupos a partir do que Pollak, designa de "a impossibilidade de ocorrência de mudanças".

Um problema grave que também se reflete na nossa participação como profissionais de museus, quando sabemos da intencionalidade no processo de interpretação e ressignificação dos objetos, por serem esses novos significados que darão o respaldo

${ }^{8}$ A exposição intitulada "MAFRO pela vida contra o genocídio da juventude negra", aconteceu no período de maio a outubro de 2015. 
Não me olhe como vê: o não lugar das memórias, ...

para a construção dos novos discursos de poder e representação nesses espaços.

Daí, analisarmos a partir ainda do pensamento de Pollak quando assegura o papel de relevância do historiador no processo que ele define como "enquadramento da memória", e que nesse sentido, a memória política pode ser motivo de várias disputas em distintas organizações, é que creio que essa memória quando enquadrada e institucionalizada, passa a enfrentar outros desafios que a partir da organização e suas interlocuções com seus pares, nos museus, vai necessitar de uma nova interpretação que atenda e corresponda às práticas que vão ter o consentimento desses aliados.

Nessa perspectiva, silenciar ou esquecer memórias no processo de preservação, tanto na etapa de eleição das coleções ou no ato de documentar, conservar e expor é um processo de natureza política, ideológica e filosófica.

Assim, os(as) gestores(as) de museus ao inserirem em suas políticas institucionais a representação das mulheres negras que permitam evidenciar narrativas e trajetórias, que as desloquem do contexto da escravização e do lugar da "subalterna", não estará somente promovendo uma construção de um novo discurso para a historiografia oficial, mas, não incentivando as práticas de racismo e de desrespeito às mulheres negras.

Pensar os museus é não apenas compreender seus espaços a partir da exposição, mas também, refletir o que não se expõe, ao levar em consideração a responsabilidade dos profissionais de museus no processo de hierarquização dos objetos que culmina no lugar de cada um deles dentro ou fora dos 'porões", contradizendo o sentido da reserva técnica.

\footnotetext{
${ }^{9}$ Utilizei do termo "porões", também na Dissertação já mencionada, "não para definir as Reservas Técnicas, mas sim, fazer uma analogia aos locais em que são amontoados e esquecidos os objetos e documentos que guardam as narrativas, trajetórias e memórias das mulheres negras e que não são disponibilizadas nos espaços institucionalizados de memória". (Silva, 2015, p. 17).
} 
Reitero ser o museu um lugar de poder e por isso, local de conflitos que acabam provocando tensões, mas acredito que vivemos em um mundo cada vez mais interligado através da tecnologia que encurtou distâncias entre povos, porém, cada vez mais, nos isolamos em nossos mundos, o que também se reflete em nossos espaços de trabalho.

Acredito que podemos transformar esses locais de aparentemente desencontros dos fatos, em caminhos que permitam estreitar uma possibilidade de encontros e reencontros, pois, é necessário que pensemos no sujeito enquanto os verdadeiros patrimônios por serem eles os nossos mais seguros registros de memórias.

Dependem do esforço dos profissionais de museus fazer dos objetos museológicos, pontes para as descobertas dos sujeitos e de estímulo para o fortalecimento do sentimento de pertença dos indivíduos, nesses espaços.

Preservar é um ato político e são os nossos repertórios ideológicos que irão nortear o lugar onde queremos assegurar as trajetórias e as narrativas dos vários sujeitos. É preocupante estar em 2016, mais de 300 anos depois da Abolição e perceber a ausência de espaços de memórias sobre a mulher negra que retrate de forma profissional e ética, a participação das mesmas no cenário econômico, político e cultural do país sem uma alusão fetichizada à escravidão, pois, as leituras e releituras que temos da historiografia são de obras que reproduzem a figura da mulher negra nos museus em ambientações criadas com cadeiras de arruar, balangandãs, dentre outras.

Logo, encontramos nessas mostras ou nas narrativas produzidas pelas mesmas, através de catálogos, legendas que remetem o público ao mesmo contexto da escravidão através de títulos: "balangandãs de escravas", "saias de escravas", "roupas de crioulas", "ama de leite" etc., reafirmando Hooks (2005), quando diz, "a figura da negra quase sempre é associada ao "estereótipo" 
Não me olhe como vê: o não lugar das memórias, ...

da mãe preta" [...], e reitera, "[...] essa imagem registra a presença feminina negra como significada pelo corpo, neste caso, a construção de mulher como mãe, peito, amamentando e sustentando a vida de outros." (p. 469).

Em determinados momentos, percebemos na subjetividade das exposições, os discursos aparentemente ditos casuais ou não intencionais. Mas, as ausências dos nomes das donas das peças, das referências dadas a esses objetos, reiteram nesses projetos expográficos, que as mulheres negras não tiveram o mesmo tratamento que as mulheres não negras. Não lhes deram nomes, nem filiação.

O que me leva a inquietante indagação: em qual contexto se dão essas representações, as relações estabelecidas dessas mulheres com seus pares? Quantas mulheres não foram escravizadas? E quando escravizadas, quais foram as relações no processo de troca de favores entre as mulheres e homens não negros, nesse período?

E os seus filhos e filhas? E as relações de afetividade dessas mulheres na condição de escravizadas? Serem amas-de-leite era uma tarefa de prazer para essas mulheres? Os museus se eximem de revolver de suas narrativas as relações das mulheres negras e as famílias exploradoras.

Brazil e Shumaher (2007) destacam as consequências que as atividades de amas-de-leite tinham para "a constituição das famílias escravizadas", ( p. 44) quando afirmam que,

A disponibilidade do leite de uma ama, implicava necessariamente no afastamento de seus filhos, os quais sob o ponto de vista dos escravocratas, seriam de pouca ou nenhuma serventia. Ao 'alugarem ou adquirem amas-de-leite', viam suas 'crias' como um gasto adicional, além de pensarem ser inadmissivel a partilha dos seios da cativa entre os seus filhos brancos e os "negrinhos". As consequências inevitáveis dessas brutalidades da casa-grande traduziram-se na negação da maternidade de muitas escravizadas e na alta taxa de mortalidade de suas crianças. (p. 44-45). 
A partir do que os autores relatam, reforça a isenção dos museus ao maquiarem nas suas exposições "[...] as atrocidades do sistema escravista". Ao mesmo tempo em que ocultam representações de mulheres africanas, que "ajudaram a estruturar e reorganizar sociedades que entre si articulavam estratégias de resistência. Instalaram negócios e estabeleceram continuamente redes de comunicação entre os continentes". (Brazil \& Shumaher, 2007, p. 44-62)

Dessa forma, as instituições museológicas de Salvador, Bahia, Brasil, se querem trazer para as suas exposições de longa duração a escravidão, que narrem as histórias que se encontram em registros documentais, em vários suportes: cartas, diários etc., salvaguardados em arquivos oficiais e particulares e também em produções literárias, já no mercado.

As marcas desse período se espalham ainda hoje pelo mundo através das várias formas de racismo e, os museus aqui apresentados, ainda estão mergulhados nas lembranças saudosistas e estereotipadas quando não, fetichizada ao legitimar as coleções de adereços e joias, vestes e mobiliário, como memórias que para mim, no contexto em que se encontram, só reforçam a validação da superioridade hegemônica de uma classe sobre a outra.

E como afirma Halbwachs (2003),

Para que a nossa memória se aproveite da memória dos outros, não basta que estes nos apresentem seus testemunhos; também é preciso que ela não tenha deixado de concordar com as memórias deles e que existam muitos pontos de contato entre uma e outras para que a lembrança que nos fazem recordar venha a ser reconstruída sobre uma base comum. (p. 39)

A partir dessa assertiva, considero que os museus não se utilizam da escuta das vozes das mulheres negras, presentes nos vários suportes materiais e imateriais para fazer reverberar em ecos 
Não me olhe como vê: o não lugar das memórias, ...

que possibilitem a reflexão do público sobre esses discursos. Com isso, esquecem-se de divulgarem a memória de mulheres que construíram a nossa história como guerreiras, literatas, ativistas etc. São elas: Dandara, Acotirene, Luíza Mahin, Tereza de Benguela, Maria Felipa, Zeferina, Carolina de Jesus, Lélia Gonzalez, Neuza Santos Souza dentre outras. Não podemos mais viver de imaginação e de suposições advindas de ausências, pois acabaremos reproduzindo a cultura do silêncio e do esquecimento.

\section{A discussão sobre as mulheres negras na Museologia: teoria ou militância?}

Seguindo este raciocínio ponho uma questão aos leitores, esta minha produção é teoria ou militância e qual o demérito se as duas instâncias estiverem (ou não) em comunhão? Se militância pode ser definida por "prática da pessoa que defende uma causa, de quem busca a transformação da sociedade através da ação: militância política, social, estudantil" e se a teoria, de acordo com o próprio dicionário, a depender do sentido que a palavra emprega, pode ser suposição, ideia, princípio, especulação, até mesmo abstração, posso assim considerar no contexto da abstração que a mesma emprega-se à teoria dos que se colocam a falar de negros(as) utilizando do tema como seus objetos de pesquisa, mas, com uma pequena diferença - mas que a Academia não Ihe cobra - estar fora dos seus lugares de fala.

Ao defender a causa de que as memórias das mulheres negras devem estar compondo os conteúdos das exposições museológicas que tratam de sociedade, de grupos sociais, de fatos históricos; ao questionar que os museus quando reproduzem a imagem da escravizada, respaldados pelo ideário de que as mesmas só participaram dessa parte da história e que só podem compor o discurso de dominação da branca sobre a negra, ao mesmo tempo em que o discurso de que o corpo da mulher negra é o suporte das memórias deixadas por ricos(as) e brancos(as), não é estar apenas militando, mas sim, estar epistemologicamente conjecturando a 
partir de uma prática costumeira da sociedade de alocar-lhes nos não lugares.

Comungo do pensamento de Fanon (2008), quando diz que, "a arquitetura do presente trabalho situa-se na temporalidade. Todo problema humano exige ser considerado a partir do tempo. Sendo ideal que o presente sempre sirva para construir o futuro." (p. 29).

Assim, enquanto sujeito produtora de conhecimento, devo me eximir das causas sociais que afligem a mim e aos meus pares e aos tantos outros sujeitos injustiçados pela sociedade hegemônica, como por exemplo, as crianças em situação de risco, para me adequar a um modelo excludente, visível nas ações dos museus?

Ao sair desse cenário e produzir as minhas inquietações corro o risco de não ser legitimamente reconhecida como acadêmica e de ser descredenciada como teórica e ser outorgada apenas com o título militante. Hooks (2013) tem algo a nos dizer sobre isso, quando afirma,

Cheguei á teoria porque estava machucada - a dor dentro de mim era tão intensa que eu não conseguiria continuar vivendo. Cheguei à teoria desesperada, querendo compreender aprender o que estava acontecendo ao redor e dentro de mim. Mais importante, queria fazer a dor ir embora. Vi na teoria, na época, um local de cura. (p. 83).

Nas palavras da autora, me reservo o direito de afirmar que ao trazer novas discussões para o campo da museologia e consequentemente dos museus, considero estar construindo ainda o discurso do não aceitável. Ao escrever sobre a representação das mulheres negras nos museus de Salvador, Bahia, Brasil, buscando aporte teórico quero reforçar o meu lugar de mulher negra, enquanto museóloga negra, que encontra "incômodos" na epistemologia trazida nos pressupostos museológicos e que ainda não dão conta de um novo repensar sobre o nosso lugar de forma respeitosa e justa nos museus. São as feridas abertas pelos arranjos 
Não me olhe como vê: o não lugar das memórias, ...

sociais, construídos para vivermos em comum acordo na família, na escola, no trabalho etc.

Falar desse tema nesse tempo é mais do que providencial, para não dizer estratégico, já que estratégia sempre foi a forma que a sociedade branca - a elite intelectual e política - "inventou" para nos inserir na dinâmica do bem viver. A invenção tomou forma, autonomia e está aqui para assegurar o seu lugar de fala. Há um ato de identificação, como afirma Mbembe (2014),

$<<$ eu sou um negro >> $\mathrm{O}$ ato de identificação constitui a resposta a uma pergunta que se faz; $<<$ Quem sou eu, portanto? >>; ou que nos é feita: <<Quem são vocês?〉> [...] O acto de identificação é igualmente uma afirmação de existência. <<Eu sou〉> significa, desde logo, eu existo. (p. 255).

As palavras do autor me permitem arvora-me e continuar a escrever, a falar. Só assim estaremos "cicatrizadas". A construção de uma teoria ainda que possa ser considerada somente militância, é a minha cura. Hooks (2013) reitera a minha afirmação quando diz,

Quando nossa experiência vivida da teorização está fundamentalmente ligada a processos de autorrecuperação, de libertação coletiva, não existe brecha entre a teoria e a prática. Com efeito, o que essa experiência mais evidencia é o elo entre as duas - um processo que, em última análise, é recíproco, onde uma capacita a outra. (p. 86)

E coadunando com o pensamento da autora, a teoria só é libertadora, curadora e revolucionária quando permitimos que ela cumpra esse papel. O que posso afirmar é que tratar dos temas, mulheres negras, memórias, narrativas, trajetórias, representação, gênero, subalternidades e museus, torna-me ainda mais cumpridora, do meu papel como museóloga e cidadã. Por isso, proponho que façamos a Diáspora para nos fortalecer, através das memórias aportadas nos vários suportes materiais que os museus 
e/ou a Academia, com muita apropriação, guardam nos lugares ainda não pesquisados.

\section{Referências}

Brasil. (2003). Estatuto da Igualdade Racial. Brasília: [Senado Federal].

Brasil. (2009). Estatuto dos Museus. Disponível em:

http://www.planalto.gov.br/ccivil_03/_Ato2007-2010/2009/ Lei/ L11904.htm

Brasil. (2010). Lei n. 12.288, de 20 de julho de 2010. Institui o Estatuto da Igualdade Racial; altera as Leis $\mathrm{n}^{\text {os }} 7.716$, de 5 de janeiro de 1989, 9.029, de 13 de abril de 1995, 7.347, de 24 de julho de 1985, e 10.778, de 24 de novembro de 2003. Disponível em: http://www.planalto.gov.br/ccivil_03/_ato20072010/2010/lei/l12288.htm

Cury, M. X. (2005). Exposição: concepção, montagem e avaliação. São Paulo: Annablime, 2005.

Dicionário Online de Português. Disponível em:

http://www.dicio.com.br/militancia.

Fanon, F. (2008). Pele negra, máscaras brancas. (R. Silveira, Trad.). Salvador: EDUFBA.

Farelli, N. H. (1981). Balangandãs e Figas da Bahia: o poder mágico dos amuletos. Rio de Janeiro: A. C. Fernandes.

Freire, P. (1989). Educação como prática de liberdade. Rio de Janeiro: Paz e Terra.

Godoy, S. de S. (2006). Círculo das contas: jóias de crioulas baianas. Salvador: Fundação Museu Carlos Costa Pinto.

Halbwachs, M. (2003). A Memória Coletiva. São Paulo: Centauro.

Hooks, B. (2013). Ensinando a transgredir: a educação como prática da liberdade. São Paulo: Martins Fontes.

Instituto Feminino da Bahia. Museu Henriqueta Catharino. Disponível em: 
Não me olhe como vê: o não lugar das memórias, ...

http://www.institutofeminino.org.br/museu_henriqueta_catha rino/index.php?local=museu_henriqueta_catharino

Mbembe, A. (2014). A crítica da razão negra. Lisboa: Antígona Editores Refractários.

Menezes, U. T. B. Do Teatro da Memória ao Laboratório da História:

a exposição museológica e o conhecimento histórico.

Disponível em:

http://www.scielo.br/pdf/anaismp/v2n1/a02v2n1.pdf

Museu Eugênio Teixeira Leal. Informações do perfil.

Disponível em:

http://museologiaporto.ning.com/profile/MuseuEugenioTeixeir aLeal

Pollak, M. (1992). Memória e identidade social. Estudos Históricos, Rio de Janeiro, 5 (10), 200-212.

Disponível em:

https://www.google.com.br/url?sa=t\&rct=j\&q=\&esrc=s\&source $=$ web $\& c d=1 \&$ cad $=$ rja $\&$ uact $=8 \&$ ved $=0 C B 0 Q F j A A a h U K E w j-$ qc_J35nIAhWCj5AKHRZUArE\&url=http\%3A\%2F\%2Fbibliotecadig ital.fgv.br\%2Fojs\%2Findex.php\%2Freh\%2Farticle\%2Fdownload \%2F1941\%2F1080\&usg=AFQjCNFlqt2VHES91phrtdR18NXs8AbG Ew\&sig2=tfex1obcNSOkQwiShWRk9w

Silva, J. A. F. (2015). A representação das mulheres negras negras nos museus de Salvador: uma análise em branco e preto. Dissertação. Universidade Federal da Bahia, Salvador.

Schumaher, S., \& Vital Brasil, É. (2007). Mulheres Negras do Brasil. Rio de Janeiro: SENAC Nacional.

The International Council of Museums. Disponível em: http://icom.museum/ 
Joana Angélica Flores Silva

208 